\title{
The use of shaded fuelbreaks in landscape fire management
}

\author{
James K. Agee ${ }^{\mathrm{a}, *}$, Berni Bahro ${ }^{\mathrm{b}}$, Mark A. Finney ${ }^{\mathrm{c}}$, Philip N. Omi ${ }^{\mathrm{d}}$, David B. Sapsis ${ }^{\mathrm{e}}$, \\ Carl N. Skinner ${ }^{\mathrm{f}}$, Jan W. van Wagtendonk ${ }^{\mathrm{g}}$, C. Phillip Weatherspoon ${ }^{\text {h }}$ \\ ${ }^{\mathrm{a}}$ College of Forest Resources Box 352100, University of Washington, Seattle, WA 98195, USA \\ b Placerville Ranger District, El Dorado National Forest, Camino, CA 95667, USA \\ ${ }^{\mathrm{c}}$ Systems for Environmental Management, Missoula MT 59802, USA \\ ${ }^{\mathrm{d}}$ Western Forest Fire Research Center (WESTFIRE), Department of Forest Sciences, Colorado State University, Ft. Collins, CO 80523, USA \\ ${ }^{\mathrm{e}}$ University of California in Davis, Davis, CA 95814, USA \\ ${ }^{\mathrm{f}}$ USDA Forest Service, Pacific Southwest Research Station, Redding, CA 96001, USA \\ ${ }^{\mathrm{g}}$ US Geological Survey, Biological Resources Division, Yosemite Field Station, El Portal, CA 95318, USA \\ ${ }^{\mathrm{h}}$ USDA Forest Service, Pacific Southwest Research Station, Redding, CA 96001, USA
}

Accepted 12 March 1999

\begin{abstract}
Shaded fuelbreaks and larger landscape fuel treatments, such as prescribed fire, are receiving renewed interest as forest protection strategies in the western United States. The effectiveness of fuelbreaks remains a subject of debate because of differing fuelbreak objectives, prescriptions for creation and maintenance, and their placement in landscapes with differing fire regimes. A well-designed fuelbreak will alter the behavior of wildland fire entering the fuel-altered zone. Both surface and crown fire behavior may be reduced. Shaded fuelbreaks must be created in the context of the landscape within which they are placed. No absolute standards for fuelbreak width or fuel reduction are possible, although recent proposals for forested fuelbreaks suggest $400 \mathrm{~m}$ wide bands where surface fuels are reduced and crown fuels are thinned. Landscape-level treatments such as prescribed fire can use shaded fuelbreaks as anchor points, and extend the zone of altered fire behavior to larger proportions of the landscape. Coupling fuelbreaks with area-wide fuel treatments can reduce the size, intensity, and effects of wildland fires. (C) 2000 Elsevier Science B.V. All rights reserved.
\end{abstract}

Keywords: Prescribed fire; Thinning; Forest fire; Western United States

\section{Introduction}

Fuelbreaks have a long history in the western United States, and interest in them has waxed and waned over past decades. Currently, there is renewed interest

*Corresponding author. Tel.: +1-206-543-2688; fax: +1-206543-3254.

E-mail address: jagee@u.washington.edu (J.K. Agee). in the role of shaded fuelbreaks (where some forest canopy remains) in forest landscape management. The recent interest in fuelbreaks and similar concepts has even spawned new names, such as defensible fuel profile zones and community protection zones (Omi, 1996; Weatherspoon and Skinner, 1996). The term 'fuelbreak' is used here to describe areas manipulated for the common purpose of reducing fuels to reduce the spread of wildland fires, and in forested 
areas the term is synonymous with 'shaded fuelbreak' as forest canopy is retained on site. We attempt here to describe the various key components that characterize fuelbreaks, evaluate their use, and discuss alternatives to traditional fuelbreak approaches.

A fuelbreak is 'a strategically located wide block, or strip, on which a cover of dense, heavy, or flammable vegetation has been permanently changed to one of lower fuel volume or reduced flammability' (Green, 1977). Green's definition of fuelbreak does not specifically define exactly how wide a fuelbreak may be, or exactly what kind of changes in fuel volume or reduced flammability are created. It differs from a fireline, defined by Green (1977) as 'a narrow line, 2-10 ft wide, from which all vegetation is removed down to mineral soil...' or a firebreak, 'specifically, a fireline wider than $10 \mathrm{ft}$, frequently 20-30 feet wide...'.

The effectiveness of fuelbreaks remains a subject of debate within and outside of the fire management community. There are many reasons for this broad range of opinion, among them that objectives can vary widely, fuelbreak prescriptions (width, amount of fuel reduction, maintenance standards) may also vary, they can be placed in many different fuel conditions, and may be approached by wildland fires under a variety of normal to extreme weather conditions. Furthermore, fuelbreaks are never designed to stop fires but to allow suppression forces a higher probability of successfully attacking a wildland fire. The amount of technology directed at the fire, and the requirement for firefighter safety, both affect the efficacy of fuelbreaks in the suppression effort. A major criterion of effectiveness may be economic, in balancing creation and maintenance costs against changes in wildland fire suppression expenditures and values (habitat, homes, etc.) protected from loss. Experimental treatments where fires would be ignited against fuelbreaks of varying prescriptions have not historically been possible to conduct (Davis, 1965), and estimating reductions in wildland fire losses is difficult. Recent developments in fire simulation technology (Finney, 1998) are opening up new ways to evaluate fuel treatments in the context of spatially explicit fuel mosaics and varying suppression levels.

The shaded fuelbreak concept in forested areas is the type of fuelbreak discussed here, along with area treatment such as prescribed fire. A shaded fuelbreak is created by altering surface fuels, increasing the height to the base of the live crown, and opening the canopy by removing trees. This type of fuelbreak spans a wide range of understory and overstory prescriptions and methods of creation through manual, mechanical, and prescribed fire means. The timing of the action will also be important: is it created at once, staged, or mixed with other treatments that may be occurring over time and over the landscape? Other issues associated with the residual overstory are problems with senescent or diseased trees, or economic issues of retaining harvestable overstory trees.

\section{Fire behavior theory and fuelbreaks}

The primary reason for fuelbreaks, as well as any other type of fuel treatment, is to change the behavior of a fire entering the fuel-altered zone. Fuelbreaks may also be used as points of anchor for indirect attack on wildland fires, as well as for prescribed fires. We can define the ways that forest fire behavior is altered by modification of fuels, and these principles apply to all forests where fuel treatments are applied and maintained.

\subsection{Surface fire behavior}

Surface fuel management can limit fireline intensity (Byram, 1959) and lower potential fire severity (Ryan and Noste, 1985). Operations conducted for 'forest health' can unfortunately increase fireline intensity or increase fire severity, if fuels are not appropriately managed and forest structure is altered without regard to fire resistance of the residual stand (Weatherspoon, 1996; Agee, 1997). The management of surface fuels so that potential fireline intensity remains below some critical level can be accomplished through several strategies and techniques. Among the common strategies are fuel removal by prescribed fire, adjusting fuel arrangement to produce a less flammable fuelbed (e.g., crushing), or 'introducing' live understory vegetation to raise average moisture content of surface fuels (Agee, 1996). Wildland fire behavior has been observed to decrease with fuel treatment (Helms, 1979; Buckley, 1992), and simulations conducted by van Wagtendonk (1996) found both pile burning 
and prescribed fire, which reduced fuel loads, to decrease subsequent fire behavior. These treatments usually result in efficient fireline construction rates, so that control potential (reducing 'resistance to control') can increase dramatically after fuel treatment.

The various surface fuel categories interact with one another to influence fireline intensity. Although more litter and fine branch fuel on the forest floor usually results in higher intensities, that is not always the case. If additional fuels are packed tightly (low fuelbed porosity), they may result in lower intensities. Although larger fuels ( $>3$ in.) are not included in fire spread models as they do not usually affect the spread of the fire (unless decomposed (Rothermel, 1991)), they may result in higher energy releases over longer periods of time when a fire occurs, having significant effects on fire severity, and they reduce rates of fireline construction.

The effect of herb and shrub fuels on fireline intensity is not simply predicted. First of all, more herb and shrub fuels usually imply more open conditions. These should be associated with lower relative humidities and higher surface windspeeds. Dead fuels may be drier - and the rate of spread may be higher because of the altered microclimate compared to more closed canopy forest with less understory. Live fuels with higher foliar moisture, while green will have a dampening effect on fire behavior. However, if the grasses and forbs cure, the fine dead fuel can increase fireline intensity and localized spotting. Post-fire analyses of fire damage to plantation trees after the 1987 fires in the Hayfork District of the Shasta-Trinity National Forest (Weatherspoon and Skinner, 1995) showed a positive relationship between grass cover and damage and a negative relationship between forb cover and damage, most likely because grasses were cured and forbs were not.

\subsection{Conditions that initiate crown fire}

A fire moving through a stand of trees may move as a surface fire, an independent crown fire, or as a combination of intermediate types of fire (Van Wagner, 1977). The initiation of crown fire behavior is a function of surface fireline intensity and of the forest canopy: its height above ground and moisture content (Van Wagner, 1977). The critical surface fire intensity needed to initiate crown fire behavior can be
Table 1

Flame lengths associated with critical levels of fireline intensity that are associated with initiating crown fire, using Byram's (1959) equation.

\begin{tabular}{lllll}
\hline $\begin{array}{l}\text { Foliar moisture } \\
\text { content }(\%)\end{array}$ & \multicolumn{4}{l}{ Height of crown base $(\mathrm{m})$} \\
\cline { 2 - 5 } & 2 & 6 & 12 & 20 \\
\hline 70 & 1.1 & 2.3 & 3.7 & 5.3 \\
80 & 1.2 & 2.5 & 4.0 & 5.7 \\
90 & 1.3 & 2.7 & 4.3 & 6.1 \\
100 & 1.3 & 2.8 & 4.6 & 6.5 \\
120 & 1.5 & 3.2 & 5.1 & 7.3 \\
\hline
\end{tabular}

calculated for a range of crown base heights and foliar moisture contents, and represents the minimum level of fireline intensity necessary to initiate crown fire (Table 1; Alexander, 1988; Agee, 1996). Fireline intensity or flame length below this critical level may result in fires that do not crown but may still be of stand replacement severity. For the limited range of crown base heights and foliar moistures shown in Table 1, the critical levels of flame length appear more sensitive to height to crown base than to foliar moisture (Alexander, 1988).

If the structural dimensions of a stand and information about foliar moisture are known, then critical levels of fireline intensity that will be associated with crown fire for that stand can be calculated. Fireline intensity can be predicted for a range of stand fuel conditions, topographic situations such as slope and aspect, and anticipated weather conditions, making it possible to link on-the-ground conditions with the initiating potential for crown fires. In order to avoid crown fire initiation, fireline intensity must be kept below the critical level. This can be accomplished by managing surface fuels such that fireline intensity is kept well below the critical level, or by raising crown base heights such that the critical fireline intensity is difficult to reach. In the field, the variability in fuels, topography and microclimate will result in varying levels of potential fireline intensity, critical fireline intensity, and therefore varying crown fire potential.

\subsection{Conditions that allow crown fire to spread}

The crown of a forest is similar to any other porous fuel medium in its ability to burn and the conditions under which crown fire will or will not spread. The 
heat from a spreading crown fire into unburned crown ahead is a function of the crown rate of spread, the crown bulk density, and the crown foliage ignition energy. The crown fire rate of spread is not the same as the surface fire rate of spread, and often includes effects of short-range spotting. The crown bulk density is the mass of crown fuel, including needles, fine twigs, lichens, etc., per unit of crown volume (analogous to soil bulk density). Crown foliage ignition energy is the energy required to ignite fuel, and varies primarily by foliar moisture content, and differs from heat of combustion, that may vary by species (van Wagtendonk et al., 1998). Crown fires will stop spreading, but not necessarily stop torching, if either the crown fire rate of spread or crown bulk density falls below some minimum value.

If surface fireline intensity rises above the critical surface intensity needed to initiate crown fire behavior, the crown is likely to become involved in combustion. Three phases of crown fire behavior can be described by critical levels of surface fireline intensity and crown fire rates of spread (Van Wagner, 1977, 1993): (1) a passive crown fire, where the crown fire rate of spread is equal to the surface fire rate of spread, and crown fire activity is limited to individual tree torching; (2) an active crown fire, where the crown fire rate of spread is above some minimum spread rate; and (3) an independent crown fire, where crown fire rate of spread is largely independent of heat from the surface fire intensity. Scott and Reinhardt, in prep., have defined an additional class, (4) conditional surface fire, where the active crowning spread rate exceeds a critical level, but the critical level for surface fire intensity is not met. A crown fire will not initiate from a surface fire in this stand, but an active crown fire may spread through the stand if it initiates in an adjacent stand. A 'crown-fire-safe' landscape would have characteristics such that, at most, only limited tree torching would result under severe fire weather.

Critical conditions can be defined below which active or independent crown fire spread is unlikely. To derive these conditions, visualize a crown fire as a mass of fuel being carried on a 'conveyor belt' through a stationary flaming front (Fig. 1). The amount of fine fuel passing through the front per unit time (the mass flow rate) depends on the speed of the conveyor belt (crown fire rate of spread) and the density of the forest
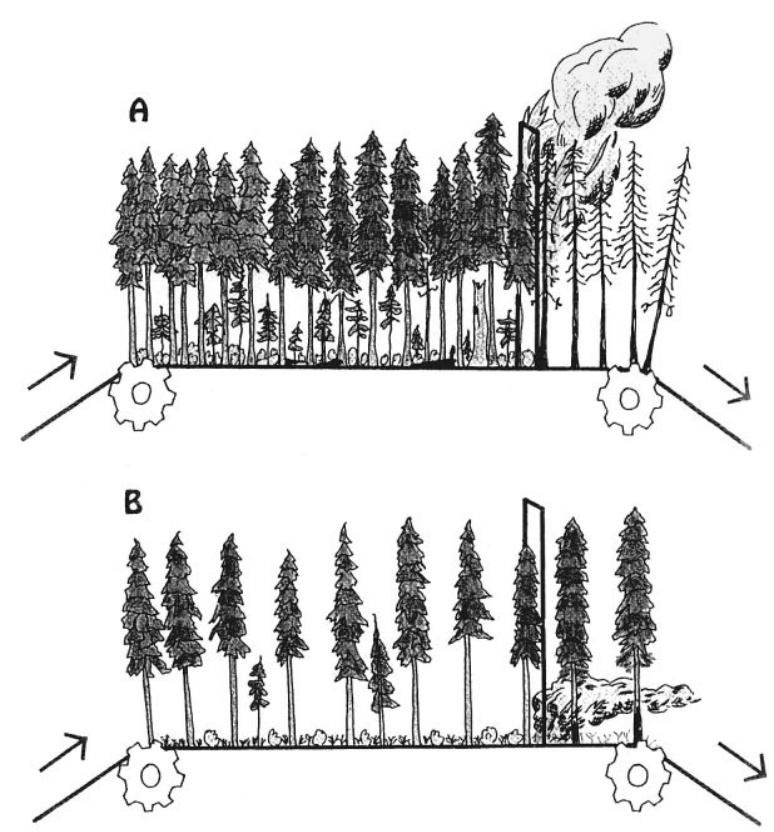

Fig. 1. Critical conditions for mass flow rate can be visualized by passing a forest along a 'conveyor belt' through a stationary flaming front. (A) Under severe fire weather and high rate of spread, crown mass passes through the flaming front rapidly and exceeds a critical mass flow rate, and crown fire occurs. (B) Where crown bulk density is lower under the same rate of spread, critical levels of mass flow rate cannot be obtained and the fire remains a surface fire. Lower crown fire rate of spread (i.e., lower windspeed), might also result in loss of crown fire activity.

crown fuel (crown bulk density). If the mass flow rate falls below some minimum level (Van Wagner, 1977) crown fires will not spread. Individual crown torching, and/or crown scorch of varying degrees, may still occur.

Defining a set of critical conditions that may be influenced by management activities is difficult. At least two alternative methods can define conditions such that crown fire spread would be unlikely (i.e. mass flow rate is too low). One is to calculate critical windspeeds for given levels of crown bulk density (Scott and Reinhardt, in prep.), and the other is to define empirically derived thresholds of crown fire rate of spread so that critical levels of crown bulk density can be defined (Agee, 1996). Crown bulk densities of $0.2 \mathrm{~kg} \mathrm{~m}^{-3}$ are common in boreal forests that burn with crown fire (Johnson, 1992), and in mixed conifer forest, Agee (1996) estimated that at 
levels below $0.10 \mathrm{~kg} \mathrm{~m}^{-3}$ crown fire spread was unlikely, but no definitive single 'threshold' is likely to exist.

Therefore, reducing surface fuels, increasing the height to the live crown base, and opening canopies should result in (a) lower fire intensity, (b) less probability of torching, and (c) lower probability of independent crown fire. There are two caveats to these conclusions. The first is that a grassy cover is often preferred as the fuelbreak ground cover, and while fireline intensity may decrease in the fuelbreak, rate of spread may increase. van Wagtendonk (1996) simulated fire behavior in untreated mixed conifer forests and fuelbreaks with a grassy understory, and found fireline intensity decreased in the fuelbreak (flame length decline from 0.83 to $0.63 \mathrm{~m}$ ( 2.7 to $2.1 \mathrm{ft}$ )) but rate of spread in the grassy cover increased by a factor of $4(0.81$ to $3.35 \mathrm{~m} / \mathrm{min}(2.7-11.05 \mathrm{ft} / \mathrm{min}))$. This flashy fuel is an advantage for backfiring large areas in the fuelbreak as a wildland fire is approaching (Green, 1977), as well as for other purposes described later, but if a fireline is not established in the fuelbreak, the fine fuels will allow the fire to pass through the fuelbreak quickly. The second caveat is that more open canopies will result in an altered microclimate near the ground surface, with somewhat lower fuel moisture and higher windspeeds in the open understory (van Wagtendonk, 1996).

\section{Fuelbreak prescriptions}

\subsection{Creation}

Fuelbreaks must be created in the context of the landscape within which they are placed. Some of the early fuelbreaks, such as the Ponderosa Way in California, were intended to separate the foothill-woodland vegetation type from the higher elevation ponderosa pine forest. Others have been designed as networks of primary and secondary fuelbreaks, with the primary ones being wider (Davis, 1965; Omi, 1977). A major implication of past linear fuel modifications, as the sole fuel treatment on the landscape, is that areas between the linear strips were 'sacrificed', in that control efforts were focused in the fuelbreaks, and significant value loss might occur in the interior of an untreated block surrounded by a fuelbreak. Hence, the relationship between potential ignition sources and fuelbreak locations becomes critical. Fuelbreaks can be created as initial fuel treatments, with the intent to follow up with more extensive landscape fuel treatments, gradually reducing potential fire damage within interior untreated areas as more of the landscape becomes treated.

No absolute standards for width or fuel manipulation are available. Fuelbreak widths have always been quite variable, in both recommendations and construction. Based on radiant heat loads from high intensity chaparral fires, Green and Schimke (1971) recommended that widths at least $65 \mathrm{~m}(200 \mathrm{ft})$ were necessary for safety considerations. A minimum of $90 \mathrm{~m}$ (300 ft) was typically specified for primary fuelbreaks (Green, 1977). As early as the 1960s, fuelbreaks as wide as $300 \mathrm{~m}(1000 \mathrm{ft})$ were included in gaming simulations of fuelbreak effectiveness (Davis, 1965), and the recent proposal for northern California national forests by the Quincy Library Group (see web site http://www.qlg.org for details) approved by the Federal Government includes fuelbreaks $400 \mathrm{~m}$ $(0.25 \mathrm{mi})$ wide. Fuelbreak simulations for the Sierra Nevada Ecosystem Project (SNEP) adopted similar wide fuelbreaks (van Wagtendonk, 1996; Sessions et al., 1996).

Fuel manipulations can be achieved using a variety of techniques (Green, 1977) with the intent of removing surface fuels, increasing the height to the live crown of residual trees, and spacing the crowns to prevent independent crown fire activity. In the Sierra Nevada, van Wagtendonk (1996) prescribed the following fuel alterations from untreated forest levels to fuelbreaks: $1 \mathrm{~h}$ timelag fuels, 6.6-2.2 t/ha (3 to $1 \mathrm{t} / \mathrm{ac}$ ); $10 \mathrm{~h}$ timelag fuels, $4.5-1.1 \mathrm{t} / \mathrm{ha}$ ( 2 to $0.5 \mathrm{t} / \mathrm{ac}) ; 100 \mathrm{~h}$ timelag fuels, 4.5-1.1 t/ha (2-0.5 t/ac); live load, 4.5$0 \mathrm{t} / \mathrm{ha}(2-0 \mathrm{t} / \mathrm{ac})$; depth, $0.3-0.15 \mathrm{~m}(1-0.5 \mathrm{ft})$, resulting in a total fuel reduction from 20.2 to $4.5 \mathrm{t} / \mathrm{ha}$ (9$2 \mathrm{t} / \mathrm{ac}$ ). In the Sierra Nevada simulations, pruning of

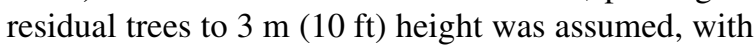
canopy cover at 1-20\% (van Wagtendonk, 1996). Canopy cover less than $40 \%$ has been proposed for the Lassen National Forest in northern California, USA (Olson, 1997). Clearly, prescriptions for creation must not only specify what is to be removed, but must describe the residual structure in terms of standard or custom fuel models so that potential fire behavior can be analyzed. 
Most fuelbreaks are located where indirect attack tactics would be employed, such as along ridges, or roads along valley bottoms (Davis, 1965; Green, 1977), and upper south and west slopes (Weatherspoon and Skinner, 1996). Fuelbreaks around developed areas have been recognized as an effective strategy (Green, 1977; Omi, 1996). Networks of fuelbreaks have been designed to confine fires to less than 400 ha (1000 acres) (Green, 1977), or to break the landscape into units less than 4000 ha (10000 acres) in size (the Quincy Library Group proposal for some northern California national forests), but Weatherspoon and Skinner (1996) suggest the appropriate extent will vary by topography and many other factors, such as 'values at risk'.

\subsection{Maintenance}

Sustained alteration of fire behavior requires effective and frequent maintenance, so that the effectiveness of any fuel treatment, including fuelbreaks, will be not only a function of the initial prescription for creation, but also standards for maintenance that are applied. The efficacy of many past fuelbreaks has been largely lost because of inadequate or no maintenance. If a fuelbreak is to remain effective, permanent cover type change must occur. Obviously, if maintenance is not done, woody vegetation will encroach, fuel loads will increase, and the effectiveness of the fuelbreak will be decreased. There are few data to evaluate effectiveness of maintenance techniques. Seeding perennial grass cover reduced brush and conifer invasion for at least 5 years in a mixed-conifer fuelbreak in California (Schimke et al., 1970), while unseeded areas were rapidly invaded by pine and brush seedlings. Restricted availability of herbicides on public lands will result in alternative techniques being more commonly used to control woody plant invasion. Manual treatment is very expensive, and mechanical treatment is only feasible on gentle terrain. Prescribed fire can be effective (Schimke and Green, 1970) but there is potential for fire escape along the edges. Late winter burns, when the previous year's production is cured, the perennials have not yet greened up, and the adjacent forest is not very flammable, may be a possible cost-effective treatment to avoid risk of escape from maintenance burns and achieve effective maintenance at low cost.

\section{Fuelbreak effectiveness}

The effectiveness of fuelbreaks continues to be questioned because they have been constructed to varying standards, 'tested' under a wide variety of wildland fire conditions, and measured by different standards of effectiveness. Green (1977) describes a number of situations where traditional fuelbreaks were successful in stopping wildland fires, and some where fuelbreaks were not effective due to excessive spotting of wildland fires approaching the fuelbreaks. One successful account from Green (1977) is from the 1971 Romero fire near Santa Barbara, CA:

If there was one successful feature in this fire it was the East Camino Cielo fuelbreak which served as final control line for approximately 12 miles. Without this fuelbreak, which enabled men, equipment, and air tankers to control that part of the fireline, it is certain that a large portion of the valuable Santa Ynez River Watershed...would have been destroyed.

An illustration of the variables important to fuelbreak effectiveness is the gaming scenario that Davis (1965) tested on experienced California Division of Forestry (CDF, now Department of Forestry and Fire Protection) personnel (Table 2). The CDF employees were asked to rate the probability of stopping wildland fires in fuelbreaks of differing width, given different levels of equipment and firefighters, and different fire behavior in adjacent fuels. Increasing the width of fuelbreaks was most effective when firefighting effort was increased (by 1963 standards when the survey was conducted) and oncoming fire behavior was not extreme.

Fuelbreak construction standards, the behavior of the approaching wildland fire, and the level of suppression each contribute to the effectiveness of a fuelbreak. Wider fuelbreaks appear more effective than narrow ones. Fuel treatment outside the fuelbreak may also contribute to their effectiveness (van Wagtendonk, 1996). Area treatment such as prescribed fire beyond the fuelbreak may be used to lower fireline intensity and reduce spotting as a wildland fire approaches a fuelbreak, thereby increasing its effectiveness. Suppression forces must be willing and able to apply appropriate suppression tactics in the fuelbreak. They must also know that the fuelbreaks exist, a common problem in the past. The effectiveness of 
Table 2

Estimated probability of stopping a wildfire at a fuelbreak under differing levels of adjacent fire behavior and suppression level. Fuelbreaks are 100 and $300 \mathrm{~m}$ wide. $\mathrm{L}=0-20 \%$ probability, or little chance of stopping the fire; $\mathrm{M}=21-50 \%$ probability, or moderate chance; $\mathrm{H}=51-$ $100 \%$ probability, or good chance (Davis, 1965). All levels based on averages of expert opinions of 10 California Division of Forestry personnel

\begin{tabular}{|c|c|c|c|c|c|c|}
\hline \multirow[t]{3}{*}{ Fire behavior level ${ }^{\mathrm{a}}$} & \multicolumn{3}{|c|}{ Suppression level: current } & \multicolumn{3}{|c|}{ Suppression level: augmented } \\
\hline & \multicolumn{6}{|c|}{ Fuelbreak width } \\
\hline & 0 (none) & $100 \mathrm{~m}$ & $300 \mathrm{~m}$ & 0 (none) & $100 \mathrm{~m}$ & $300 \mathrm{~m}$ \\
\hline Spot $0.8 \mathrm{~km}$, front $0.8 \mathrm{~km}$ & $\mathrm{~L}$ & $\mathrm{~L}$ & $\mathrm{~L}$ & $\mathrm{~L}$ & $\mathrm{~L}$ & M \\
\hline Spot $0.8 \mathrm{~km}$ front $0.16 \mathrm{~km}$ & $\mathrm{~L}$ & $\mathrm{~L}$ & M & $\mathrm{L}$ & M & $\mathrm{H}$ \\
\hline Spot $0.4 \mathrm{~km}$, front $0.8 \mathrm{~km}$ & $\mathrm{~L}$ & $\mathrm{~L}$ & $\mathrm{~L}$ & $\mathrm{~L}$ & $\mathrm{H}$ & $\mathrm{H}$ \\
\hline Spot $0.4 \mathrm{~km}$, front $0.16 \mathrm{~km}^{\mathrm{b}}$ & $\mathrm{L}$ & M & $\mathrm{H}$ & M & $\mathrm{H}$ & $\mathrm{H}$ \\
\hline
\end{tabular}

${ }^{a}$ Spotting distance of fire and front width of fire approaching the fuelbreak.

${ }^{\mathrm{b}}$ Davis' Table 14 has a typo, showing front as $0.8 \mathrm{~km}$ when it should be $0.16 \mathrm{~km}$.

suppression forces depends on level of funding for people, equipment, and aerial application of retardant, which can more easily reach surface fuels in a fuelbreak. Effectiveness is also dependent on the psychology of firefighters regarding their safety. Narrow or unmaintained fuelbreaks are less likely to be entered than wider, well-maintained ones.

Economic studies of fuelbreaks are difficult, because they must balance costs of creating and maintaining fuelbreaks against acres and dollars 'saved' because of assumed declines in burned area or reduced damage. The general approach used by Davis (1965) was to evaluate 'saved' area by superimposing past wildland fires on varying densities of planned fuelbreak systems and first defining the area which might be affected by the presence of a fuelbreak (Class 3 area, see Fig. 2). Then a proportion of that area would be estimated as 'saved', based on the average probability of control from expert opinion, depending on the level of suppression, the width of fire front, and the width of the fuelbreak. For example, if 300 ha are identified as Class 1, 700 ha as Class 2, and 500 ha identified as Class 3 for a sample wildfire and the suppression probability at the fuelbreak is $70 \%$, then the expected area saved is 350 ha $(70 \%$ of the Class 3 area). The percent reduction, or area saved, is the reduced total area of Class $1-3$ divided by the original Class $1-3$ area, or $(1-(1150 / 1500) \times 100$ $=23 \%$ ). Davis did not consider reduction of size or damage in Class 4 areas (the area of the fuelbreak), which could be significant when the fuelbreak becomes very wide (as is a typical prescription in defensible fuel profile zones). He found effectiveness was greater in timber types than brushland or grassland types, but concluded that the marginal cost of area 'saved' exceeded the benefits, at least in 1965 values, particularly for high density fuelbreaks. He cautioned that his analysis did not result in a conclusion that 'no fuelbreaks are worthwhile', and

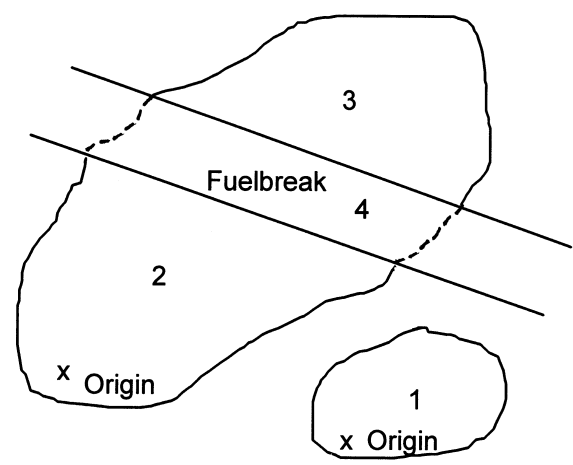

Fig. 2. An analysis of the effect of fuelbreaks on wildfire area burned and fire damage includes four types of areas: (1) those fires that never approach a fuelbreak, (2) those portions of fires that burn before the fuelbreak is encountered, (3) those portions of fires where the fuelbreak might reduce area burned if the fire is stopped before it arrives there, and (4) areas inside the fuelbreak where fire size and damage may be reduced because of the fuel treatment. Fuelbreaks can have an effect on fire size only on the Class ( 3 and 4) area, and will have an effect on reducing damage within areas burned in the Class (4) area. A transition to landscape treatment would expand the Class 4 area across more of the landscape, usually with more attention to surface fuel reduction and increasing the base to live crown, and less canopy alteration than applied to the fuelbreak. 
in fact at low levels of fuelbreak density, investments in fuelbreaks derived more benefits than investments in suppression forces.

The site-specific nature of any economic analysis of fuelbreaks is apparent from Davis' study, a primary reason that he cautioned against extrapolating his results beyond the CDF district studied in the central Sierra Nevada. Where timber types are proposed for fuelbreaks, the value of timber will offset some to all of the construction cost. As Green (1977) noted, Davis' study did not include evaluation of effectiveness under less than extreme fire behavior conditions, or the usefulness of fuelbreaks in flanking orientations to the main fire front. Also not addressed was the degree of damage within areas burned. Burn severity and level of resource damage to areas that burn outside of the fuelbreaks generally will be unaffected by the presence of the fuelbreak. In contrast, fire damage should be reduced within the fuelbreaks (and this can be a significant area for wide fuelbreaks) as in any other areas receiving effective fuel treatment (Figs. 3 and 4).

In southern California, Omi (1977) concluded that 'primary' fuelbreaks had been fairly successful in aiding fire control, but that secondary breaks had been much less successful. He noted that if age-class management were to be employed to manage chaparral fuels, with younger age classes created with prescribed fire being less flammable, the secondary fuelbreaks would be useful as places to start or control prescribed burn operations.

The question of linking fuelbreaks together into a network system is also a tough one. As individual fires are most likely to encounter one segment of fuelbreak (and hopefully be stopped there), an appropriate design for fuelbreak placement must factor in ignition potential and values at risk. Otherwise, if ignition were random and values were either regular or uniformly distributed, a fishnet approach to placement would always be preferable. A fuelbreak network in a watershed might consist of surrounding subdivisions with traditional wide fuelbreaks, while more remote areas might have much narrower fuelbreaks, perhaps not all connected to one another. These narrower fuelbreaks, with less-altered conditions, might be designed primarily as anchor points for prescribed fires. There is no a priori rule that each segment must be connected to all other segments for a fuelbreak strategy to be effective (Finney et al., in press).

\section{Landscape-level fuel treatments}

In the drier forest zones of the West, including much of the mixed-conifer forest with Douglas-fir and

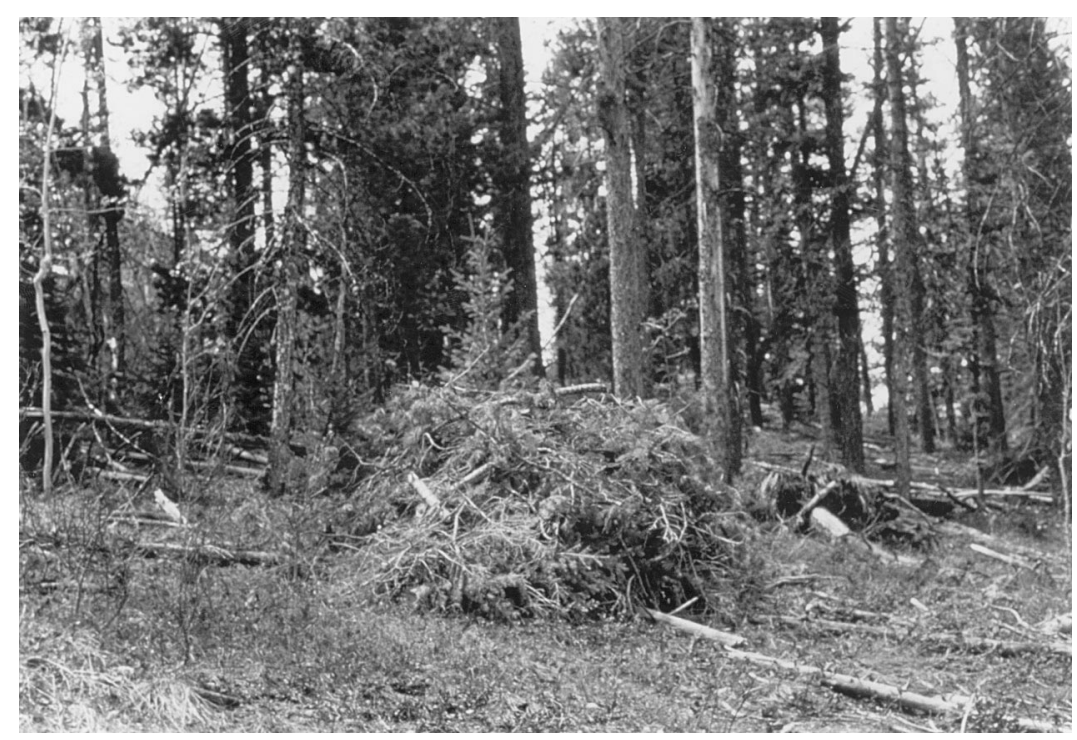

Fig. 3. Fuelbreak construction along the eastern boundary of Rocky Mountain National Park, Colorado. The treatment involved thinning of the original stand, with stem removal and hand piling prior to burning. Photo by P.N. Omi. 


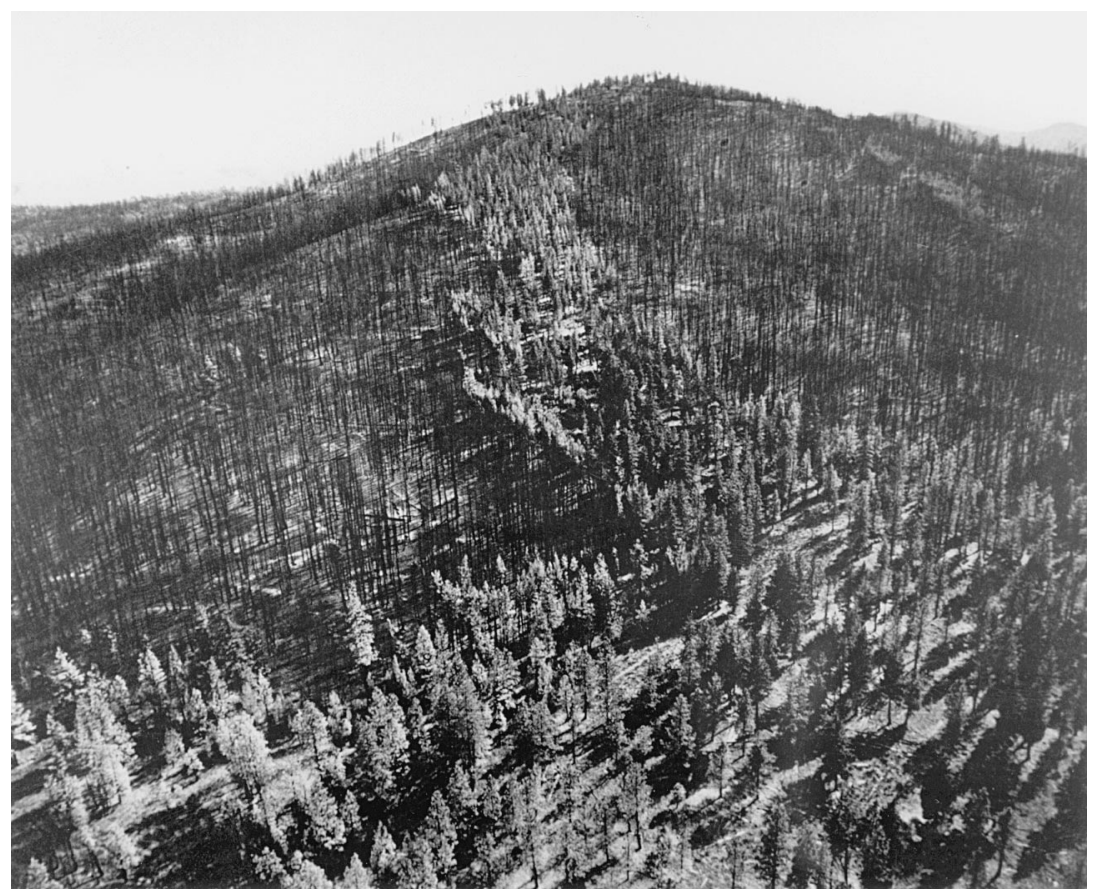

Fig. 4. Fire behavior was changed from crown to surface fire as a severe wildland fire passed through this fuelbreak on the Wenatchee National Forest, Washington. The fire then re-emerged as a crown fire on the far side. Area treatment of fuels beyond this narrow fuelbreak would have altered fire behavior over a wider area. USDA Forest Service photo.

ponderosa pine, as well as much of the pure ponderosa pine type, historical fires were primarily of low severity. Substantial changes have occurred in these forests with the exclusion of fire, as well as from harvest activity (Biswell et al., 1973; Agee, 1993). A landscape-level approach to fuels looks at the large areas as a whole (Weatherspoon and Skinner, 1996), in an attempt to fragment the existing continuous, heavy fuel in high risk areas. Fuelbreaks may be a part of that strategy but are not considered a stand-alone strategy. If utilized, the fuelbreak component of a broad fuel management strategy might best be viewed as a set of initial (perhaps 10-20 years), strategically located entries into the landscape - places from which to build out in treating other appropriate parts of the landscape - not as an end in itself. Fuelbreaks may provide a measure of protection against large fires (assuming suppression forces are present) while longer-term, area-wide treatments are being implemented. Compartmentalization of fires by fuelbreaks, which may or may not be laid out in a connected network, can help to reduce fire size but generally will not reduce damage per unit areas burned outside of the fuelbreaks themselves. Other configurations of treated areas - e.g., larger blocks that may or may not be connected (Finney et al., in press) - have been proposed for initial landscape-level treatments. Comparing the efficacy of such alternative configurations with that of fuelbreaks for reducing size and severity of large wildland fires, using newly available modeling tools (Finney, 1998; Johnson et al., 1998) would be a valuable contribution.

The word 'fragmentation' has had a notorious context since the publication of (Harris (1984) The Fragmented Forest, in which the harvesting of oldgrowth Douglas-fir forest in the Pacific Northwest was associated with loss of biodiversity. While high levels of continuous canopy may have been characteristic of northern Oregon and Washington Douglas-fir forests, west of the Cascades, high levels of structural diversity (fragmentation) were associated with historic Douglas-fir forest in the Siskiyou mountains of Oregon and California (Taylor and Skinner, 1998), and most drier forests had little fragmentation of fuel but uniformly 
very low fuel loads because of frequent fire (Agee, 1998). A trend towards more fuel fragmentation or lower fuel loads in these drier forests (essentially a diversity in fuel loading) is a trend away from severe fire and its attendant large patches and high severity. Fuel fragmentation does not have to be associated with structural fragmentation or overstory removal, but must be associated with declines in at least one of the factors affecting fire behavior discussed earlier: reduction of surface fuels and increases in height to live crown as a first priority, and decreases in crown closure as a second priority. On most landscapes these treatments should be prioritized in that order, but economic issues tend to reverse the order and focus on thinning only that directly affects crown closure. Thinning must be linked with surface fuel reduction and increases in height to live crown to be an effective fuel treatment.

Evidence for fuel treatment effects on fire behavior in the natural landscape is evident in many forest types. In the red fir forests of Yosemite, natural fires over the past 25 years have created a jigsaw puzzle of fire boundaries, with more recent fires naturally extinguishing at the edge of past fires (van Wagtendonk, 1995). In Baja California, frequent uncontrolled chaparral fires have created a fuel-buffered ecosystem where fire size is limited, in contrast to US chaparral north of the border, where fire suppression has resulted in larger expanses of continuous fuel and larger fires, even though the overall fire return intervals are similar (Minnich and Chou, 1997). Reconstructions of historic fires in eastern Washington pine forests have shown fires going out at the edges of fires that had burned 1-2 years previously (Wright, 1996). Might these effects on fire behavior and resultant size apply if area treatments were applied to today's mixed conifer forests?

A spatial simulation of fire suppression scenarios using the fire growth model FARSITE (Finney et al., in press) showed for the central California Sierra Nevada that area-wide fuel treatments (prescribed fire and thinning) similar to those of van Wagtendonk (1996) had an effect on decreasing fire size and cost, even if applied to limited areas of the landscape. Isolated, treated blocks of landscape in strategic locations slowed fire spread and decreased the potential for major fire runs, essentially allowing fire suppression forces to catch the wildland fire at smaller size and with less damage within the fireline. Lower fire size and severity may combine to lessen losses considerably, and need to be considered in economic analyses of landscape-level treatments. In the study by Finney et al. (in press), adding damage as another economic variable made the fuel treatment even more costeffective. The major economic problem is that investment in fuel treatments must be made upfront to achieve the savings when a wildland fire occurs. Funds have not been usually available for such investments until recently, when Federal policy began to allow such upfront expenditures. However, air quality constraints associated with prescribed fire may limit the area that can be treated by fire.

Area treatments, rather than being an alternative to fuelbreaks, are an expansion of the fuelbreak concept to wider areas of the landscape. Fuelbreaks are often good points to tie in control lines for prescribed fire operations. Ridgetop fuelbreaks, if tied into area treatments, could be located in areas of the landscape where the historic fire regime would likely have created more open conditions. When combined with other treatments in the landscape, they might well be created with a more light-on-the-land approach. This would recognize that some portions of landscapes (ridgetops, upper thirds of slopes, south and west aspects) would have historically experienced more frequent fires and, as a result, had more open conditions than the rest of the landscape. Fuelbreak width or canopy alteration, for example, may depend on what treatments are applied to adjacent lands to reduce excessive fuels, and need not be totally cleared areas, manually or mechanically created, straight lines, or crisscrossed grids across the landscape (Agee, 1995). 'Feathering' the canopy away from the center of the fuelbreak may be one way to create a less visually obtrusive fuelbreak. However, in terms of construction standards, a general rule of thumb will be that the less 'obvious' manipulations will usually be less effective per unit area, so that they will have to be applied over wider areas of the landscape. For example, if canopy cover was maintained above $40 \%$, surface fuel reduction and understory vegetation clearing would need to be more intensive over wider expanses. Higher levels of overstory cover, although associated with potential for independent crown fire, might also restrict the recovery of the manipulated understory and allow lengthened maintenance intervals. Maintenance is 
essential for area treatments as much as for traditional fuelbreaks, although the degree of manipulation and the maintenance schedule may vary.

\section{Conclusions}

There is a clear theoretical basis for concluding that fuelbreaks will alter fire behavior in ways amenable to limiting both the sizes of wildland fires and reducing the severity of damage from them. It is also clear that physical effectiveness of fuelbreaks depends not only on their construction specifications but on the behavior of wildland fires approaching them, and the presence and level of fire control forces. Combining fuelbreaks with area-wide fuel treatments in adjacent areas can reduce the size and intensity of wildland fires. These conclusions offer little guidance, however, in the specific design of a fuelbreak system. What criteria for construction (width, fuel treatment) should be used, where should they be placed, and how should one fuelbreak segment be linked with others? Creation of a fuelbreak network in a given area will be a sitespecific decision, and will often be part of a wider scale landscape treatment of fuels. The conclusions of Omi (1996) are especially relevant:

There will always be a role for well-designed fuelbreak systems which provide options for managing entire landscapes, including wildfire buffers, anchor points for prescribed natural fire and management-ignited fire, and protection of special features (such as urban interface developments, seed orchards, or plantations). In this context, fuelbreaks and prescribed burns should be viewed as complements to one another, rather than substitutes.

Landscape-level treatments including fuelbreaks have been proposed as a fuel management strategy that can aid wildfire control and help to achieve more broad-based ecosystem management goals (Agee and Edmonds, 1992; Weatherspoon, 1996; Weatherspoon and Skinner, 1996), particularly in areas that have historically low- to moderate-severity fire regimes (Agee, 1993). The presence of fuelbreaks in those areas may ease the application of prescribed fire treatments and allow fire control forces to conduct backfiring operations even with the bulk of forces deployed elsewhere. Fuelbreaks will not typically be stand-alone treatments, to the exclusion of either prescribed fire or the level of fire suppression capability. An appropriate combination of treatments will help to reduce unwanted wildland fire effects and the attendant ecosystem effects such fires often cause.

\section{Acknowledgements}

This paper was produced with partial funding from the Applegate Watershed Forest Simulation Project managed through the College of Forestry, Oregon State University, Corvallis, OR, USA.

\section{References}

Agee, J.K., 1993. Fire Ecology of Pacific Northwest Forests. Island Press. Washington, D.C., pp. 492.

Agee, J.K., 1995. Alternatives for implementing fire policy. In: Brown J.K., Mutch, R.W., Spoon, C.W., Wakimoto R.H. (Tech Coord.). Proceedings of the Symposium on Fire in Wilderness and Park Management. USDA Forest Service. Gen. Tech. Rep. INT-GTR-320, pp. 107-112.

Agee, J.K., 1996. The influence of forest structure on fire behavior. In: Proceedings of 17 th Forest Vegetation Management Conference. Redding, CA, pp. 52-68.

Agee, J.K., 1997. The severe weather wildfire - too hot to handle? Northwest Sci. 71, 153-156.

Agee, J.K., 1998. The landscape ecology of western forest fire regimes. Northwest Sci., 24-34 (special issue).

Agee, J.K., Edmonds, R.L., 1992. Forest protection guidelines for the northern spotted owl. In: Recovery Plan for the Northern Spotted Owl USDI Fish and Wildlife Service. Washington, D.C. Appendix F.

Alexander, M.E., 1988. Help with making crown fire hazard assessments. In: Fischer, W.C., Arno S.F. (Compilers), Protecting People and Homes from Wildfire in the Interior West. Proceedings of the Symposium and Workshop. USDA Forest Service Gen. Tech. Rep. INT-251. pp. 147-156.

Biswell, H.H., Kallander, H.R., Komarek, R., Vogl, R.J., Weaver, H., 1973. Ponderosa fire management. Tall Timbers Research Station Misc, Publication No. 2. Tall Timbers Research Station, Tallahassee, FL, pp. 49.

Buckley, A.J., 1992. Fire behaviour and fuel reduction burning: Bemm River wildfire, October 1988. Australian Forestry 55, 135-147.

Byram, G.M., 1959. Combustion of forest fuels. In: Brown, K.P. (Ed.), Forest Fire: Control and Use. McGraw-Hill, New York, pp. 584.

Davis, L.S., 1965. The economics of wildfire protection with emphasis on fuel break systems. California Division of Forestry. Sacramento, CA. pp. 166.

Finney, M.A., 1998. FARSITE: fire area simulator. Model Development and Evaluation. USDA Forest Service Research Paper RMRS-RP-4. 
Finney, M.A., Sapsis, D.B., Bahro, B. Use of FARSITE for simulating fire suppression and analyzing fuel treatment economics. In: Proceedings of the Fire in California Ecosystems: Integrating Ecology, Prevention, and Management, 17-20 November 1997, San Diego, in press.

Green, L.R., 1977. Fuelbreaks and other fuel modification for wildland fire control. USDA Agr. Hdbk. 499.

Green, L.R., Schimke, H.E., 1971. Guides for fuel-breaks in the Sierra Nevada mixed-conifer type. USDA Forest Service, Pacific Southwest Forest and Range Expt. Station, Berkeley, CA.

Harris, L., 1984. The Fragmented Forest. University of Chicago Press, Chicago, IL, pp. 211.

Helms, J.A., 1979. Positive effects of prescribed burning on wildfire intensities. Fire Management Notes 40, 10-13.

Johnson, E.A., 1992. Fire and Vegetation Dynamics: Studies from the North American boreal forest. Cambridge University Press, Cambridge, UK, pp. 129.

Johnson, K.N., Sessions, J., Franklin, J., Gabriel, J., 1998. Integrating wildfire into strategic planning for Sierra Nevada forests. J. Forestry 96, 42-49.

Minnich, R.A., Chou, Y.H., 1997. Wildland fire patch dynamics in the chaparral of southern California and northern Baja California. Int. J. Wildland Fire 7, 221-248.

Olson, R., 1997. Appraising a forest fuel treatment: The DFPZ Concept. Lassen National Forest (unpublished mimeo).

Omi, P.N., 1977. A case study of fuel management performances, Angeles National Forest, 1960-1975. In: Mooney, H.A., Conrad, C.E. (Tech. Coords). Proceedings of the Symposium on the Environmental Consequences of Fire and Fuel Management in Mediterranean Ecosystems. USDA Forest Service Gen. Tech. Rep. WO-3, pp. 404-411.

Omi, P.N., 1996. The role of fuelbreaks. In: Proceedings of the 17th Forest Vegetation Management Conference. Redding, CA, pp. 89-96.

Rothermel, R.C., 1991. Predicting behavior and size of crown fires in the northern Rocky Mountains. USDA For. Serv. Gen. Tech. Rep. INT-438.

Ryan, K.C., Noste, N.V., 1985. Evaluating prescribed fires. In: Lotan, J.E et al. (Tech. Coords). Proceedings of the Symposium and Workshop on Wilderness Fire. USDA Forest Service Gen. Tech. Rep. INT-182, pp. 230-238.

Scott, J.H., Reinhardt, E.D. A model for assessing crown fire hazard. Systems for Environmental Management. Missoula, Montana (draft report) (in preparation).

Schimke, H.E., Green, L.R., 1970. Prescribed fire for maintaining fuel-breaks in the Sierra Nevada. USDA Forest Service, Pacific Southwest Forest and Range Expt. Station. Berkeley, CA.
Schimke, H.E., Green, L.R., Heavilin, D., 1970. Perennial grasses reduce woody plant seedlings ... on mixed conifer fuel-break. USDA Forest Service Res. Note PSW- 203.

Sessions, J., Johnson, K.N., Sapsis, D., Bahro, B., Gabriel, J.T., 1996. Methodology for simulating forest growth, fire effects, timber harvest, and watershed disturbance under different management regimes. Sierra Nevada Ecosystem Project: Final Report to Congress, Addendum, University of California, Davis, Centers for Water and Wildland Resources Report 40, pp. $115-174$.

Taylor, A.H., Skinner, C.N., 1998. Fire history and landscape dynamics in a late- successional reserve, Klamath Mountains, CA, USA. For. Ecol. Manage. 111, 285-301.

Van Wagner, C.E., 1977. Conditions for the start and spread of crown fire. Canad. J. For. Res. 7, 23-34.

Van Wagner, C.E., 1993. Prediction of crown fire behavior in two stands of jack pine. Canad. J. For. Res. 23, 442-449.

van Wagtendonk, J.W., 1995. Large fires in wilderness areas. In: Brown, J.K., Mutch, R.W., Spoon, C.W., Wakimoto, R.H. (Tech. Coord.). Proceedings of the Symposium on Fire in Wilderness and Park Management. USDA Forest Service Gen. Tech. Rep. INT-GTR-320, pp. 113-116.

van Wagtendonk, J.W., 1996. Use of a deterministic fire growth model to test fuel treatments. In: Sierra Nevada Ecosystem Project: Final Report to Congress, vol. II. Assessments and Scientific Basis for Management Options. University of California, Davis. Centers for Water and Wildland Resources, pp. $1155-1165$.

van Wagtendonk, J.W., Sydoriak, W.M., Benedict, J.M., 1998. Heat content variation of Sierra Nevada conifers. Int. J. Wildland Fire 8, 147-158.

Weatherspoon, C.P., 1996. Fire-silviculture relationships in Sierra forests. In: Sierra Nevada Ecosystem Project: Final Report to Congress, vol. II, Assessments and Scientific Basis for Management Options. University of California, Davis, Centers for Water and Wildland Resources, pp. 1167-1176.

Weatherspoon, C.P., Skinner, C.N., 1995. An assessment of factors associated with damage to tree crowns from the 1987 wildfires in northern California. For. Sci. 41, 430-451.

Weatherspoon, C.P., Skinner, C.N., 1996. Landscape-level strategies for forest fuel management. In: Sierra Nevada Ecosystem Project: Final Report to Congress, vol. II, Assessments and Scientific Basis for Management Options. University of California, Davis, Centers for Water and Wildland Resources, pp. 1471-1492.

Wright, C.S., 1996. Fire history of the Teanaway River drainage, Washington. M.S. Thesis, University of Washington, Seattle, 190 pp. 